\title{
Pituitary-Adrenal Cortical Responses to Low-Dose Physostigmine and Arginine Vasopressin Administration in Normal Women and Men
}

Robert T. Rubin, M.D., Ph.D., L. Kathleen Sekula, R.N., Ph.D., Susan O'Toole, R.N., C.S., M.S.N., Michael E. Rhodes, Ph.D., and R. Kenneth Czambel, B.S.

Animal studies indicate that central cholinergic neurotransmission stimulates CRH secretion, but several human studies suggest that the hypothalamo-pituitaryadrenal cortical (HPA) axis may be activated only by doses of cholinergic agonists that produce noxious side effects and, by inference, a nonspecific stress response.

Physostigmine (PHYSO), a reversible cholinesterase inhibitor, was administered to normal women and men at a dose that elevated plasma $A C T H_{1-39}$, cortisol, and arginine vasopressin $(A V P)$ concentrations but produced few or no side effects. Exogenous AVP also was administered alone and following PHYSO, to determine if it would augment the effect of PHYSO on the HPA axis. Fourteen normal women and 14 normal men matched to the women on age and race underwent four test sessions 5 to 7 days apart: PHYSO (8 $\mu \mathrm{g} / \mathrm{kg}$ IV), AVP (0.08 U/kg IM), PHYSO plus $A V P$, and saline control. Serial blood samples taken before and after pharmacologic challenge were analyzed for ACTH ${ }_{1-39}$, cortisol, and AVP. PHYSO and AVP administration produced no side effects in about half the subjects and mild side effects in the other half, with no significant female-male differences overall. There also were no significant female-male differences in $\mathrm{ACTH}_{1-39}$ or cortisol responses to AVP. In contrast, the men had significantly greater $A C T H_{1-39}$ responses to $\mathrm{PHYSO}$ administration than did the women. The endogenous AVP response to $P H Y S O$ also was significantly greater in the men than in the women, and the ACTH $\mathrm{C}_{1-39}$ and $A V P$ responses to PHYSO were significantly correlated in the men (both $=+0.70$ ) but not in the women. None of the hormone responses was significantly correlated with the presence or absence of side effects in either group of subjects. These results indicate a greater sensitivity of the HPA axis to low-dose PHYSO in normal men than in normal women, which likely is mediated by increased secretion of AVP. The lack of difference in side effects between the two groups of subjects and the lack of significant correlations between presence or absence of side effects and hormone responses in either group suggest that the increased hormone responses in the men were due to increased responsivity of central cholinergic systems and not to a nonspecific stress response.

[Neuropsychopharmacology 20:434-446, 1999]

(C) 1999 American College of Neuropsychopharmacology. Published by Elsevier Science Inc.
From the Center for Neurosciences Research, MCP Hahnemann School of Medicine, Allegheny University of the Health Sciences, Pittsburgh, Pennsylvania.

Address correspondence to: Dr. Robert T. Rubin, Center for Neurosciences Research, Allegheny General Hospital, 320 East North Ave., Pittsburgh, PA 15212-4772.

Received March 20, 1998; revised July 1, 1998; accepted July 10, 1998
KEY WORDS: Cholinergic; Physostigmine; AVP; ACTH; Cortisol; Sex differences

There is ample evidence from animal studies that cholinergic neurotransmission stimulates both $\mathrm{CRH}$ and arginine vasopressin (AVP) secretion (Gregg 1985; Tuomisto and Männistö 1985; Assenmacher et al. 1987; Tsagarakis 
and Grossman 1990; Michels et al. 1991; Okuda et al. 1993; Whitnall 1993; Coiro et al. 1995; Calogero 1995; Ohmori et al. 1995), both of which stimulate ACTH secretion (Rivier et al. 1990; Antoni 1993). Several studies in humans, however, suggest that the hypothalamo-pituitary-adrenal cortical (HPA) axis is activated only by doses of cholinergic agonists that produce noxious side effects, especially nausea (Carroll et al. 1980; Davis et al. 1982; Doerr and Berger 1983; Nurnberger et al. 1983; Lewis et al. 1984; Krieg et al. 1987; Freeman et al. 1990), and, by inference, a nonspecific stress response, nausea being a powerful stimulus to AVP release (Nussey et al. 1988; Koch et al. 1990; Kohl 1992). In the present study, a dose of physostigmine (PHYSO), a reversible cholinesterase inhibitor, was established that discernibly elevated plasma ACTH and cortisol concentrations in normal subjects but produced few or no side effects. The purpose was to develop a pharmacologic cholinergic challenge to the central nervous system as specific as possible, with which to test the cholinergic overactivity hypothesis of major depression (Dilsaver 1986; Janowsky and Overstreet 1995), as reflected by HPA axis hormone responses in patients compared to controls.

Under the hypothesis that a low, minimal side-effect producing dose of PHYSO would enhance the secretion of CRH into the pituitary portal plexus to a certain degree but might not produce a significant ACTH response by itself in some subjects, PHYSO was given both alone and followed by a second stimulus to ACTH secretion, a similarly low dose of AVP. Both normal women and normal men participated in the dose-finding studies. This report presents differences between women and men in their hormone responses to the drug challenges.

\section{SUBJECTS AND METHODS}

\section{Development of a Low-Dose Physostigmine/AVP Challenge Test}

Lewis et al. (1984) found that, following peripheral cholinergic blockade, a PHYSO dose of $18 \mu \mathrm{g} / \mathrm{kg}$ (IV over $30 \mathrm{~min}$ ) produced both unpleasant side effects (i.e., nausea, fatigue, headache) and increased ACTH and cortisol secretion in five normal men, whereas lower doses (6 and $12 \mu \mathrm{g} / \mathrm{kg}$ ) produced neither side effects nor HPA axis activation. Coiro et al. (1995) also reported no side effects in normal men given PHYSO $12.5 \mu \mathrm{g} / \mathrm{kg}$ infused over $10 \mathrm{~min}$. We therefore began dose-finding studies in normal subjects with PHYSO $(12 \mu \mathrm{g} / \mathrm{kg}$, IV over 1 to $2 \mathrm{~min})$ and a dose of AVP $(0.18 \mathrm{U} / \mathrm{kg} \mathrm{IM})$ that had been shown to significantly elevate plasma ACTH in normal subjects (Kathol et al. 1989; Gispen-de Wied et al. 1992; Carroll et al. 1993). All studies were approved by the institutional review board (IRB), and written informed consent was obtained from each subject.

In the dose-finding studies, subjects were admitted to the Clinical Research Center at Harbor-UCLA Medical Center, Torrance, CA (for the first study) or the Clinical Studies Suite, Allegheny General Hospital, Pittsburgh, Pennsylvania (for subsequent studies) at 1 p.m. on separate occasions, 4 to 7 days apart. A heparin-lock catheter was inserted into an arm vein, and 6 $\mathrm{mL}$ blood was taken every $30 \mathrm{~min}$ starting at 2:30 P.M. At 5 P.M., a very light meal was given. At 5:30 P.M., glycopyrrolate $(0.2 \mathrm{mg}$ IM) was given to block the peripheral effects of PHYSO. At 6 P.M., saline or PHYSO IV was given, and at 7 P.M., saline or AVP IM was given. In the first study, the test days were AVP alone, PHYSO plus AVP, and scopolamine, in random order. Scopolamine had no measurable effect on ACTH or cortisol secretion. In subsequent studies, the test days were, in random order, saline at both 6 and 7 P.M. (control day), PHYSO at 6 P.M. and saline at 7 P.M. (PHYSO day), saline at 6 P.M. and AVP at 7 P.M. (AVP day), and PHYSO at 6 P.M. an AVP at 7 P.M. (PHYSO/AVP day).

Blood was drawn every 5 min from 7 P.M. until 7:20 P.M. every $10 \mathrm{~min}$ until 8 P.M. and every $30 \mathrm{~min}$ until 10:30 P.M. (23 samples; $138 \mathrm{~mL}$ total volume). Samples were placed into chilled plastic tubes containing $100 \mu \mathrm{L}$ $15 \%$ EDTA and $50 \mu \mathrm{L} 20 \%$ sodium azide, and centrifuged for 7 to 8 minutes at $500 \times g$. Aliquots of plasma were immediately pipetted into $1.5 \mathrm{~mL}$ conical polypropylene tubes, capped, and frozen until analysis for $\mathrm{ACTH}_{1-39}$ by immunoradiometric assay (IRMA; Nichols Institute, San Juan Capistrano, California) and cortisol by radioimmunoassay (RIA), the details of which have been given earlier (Rubin et al. 1987; 1995). All samples from each subject were analyzed in duplicate in the same assay.

Table 1 presents the results of the dose-finding studies. Drug doses in the first study were too high; all subjects had side effects. The dose of AVP was lowered in the second study and women were included, but side effects still occurred, particularly in the women following PHYSO alone. The PHYSO dose was halved in the third study, but there were only weak, if any, hormone responses following PHYSO. In the final study, the PHYSO dose was increased somewhat, and clear, variable hormone responses followed. Only mild side effects occurred in a few subjects; the other subjects had no side effects following either PHYSO or AVP. The PHYSO dose is smaller than that previously reported to produce HPA axis activation, whereas on average the AVP dose is somewhat higher than the cumulative dose (4.4 U) used by Salata et al. (1988) to demonstrate an evening ACTH increase in normal subjects. Because gender differences in hormone responses were suggested in the dose-finding studies, these drug doses 
Table 1. Development of Low-Dose Physostigmine and AVP Challenge Test in Normal Subjects

\begin{tabular}{lcccc}
\hline $\begin{array}{l}\text { Number and } \\
\text { Sex of Subjects }\end{array}$ & $\begin{array}{c}\text { GLYCO IV } \\
\text { at 5:30 P.M. }\end{array}$ & $\begin{array}{c}\text { PHYSO IV } \\
\text { at 6:00 P.M. }\end{array}$ & $\begin{array}{c}\text { AVP IM } \\
\text { at 7:00 P.M. }\end{array}$ & Outcome \\
\hline Eight men & $0.2 \mathrm{mg}$ & $12 \mu \mathrm{g} / \mathrm{kg}$ & $0.18 \mathrm{U} / \mathrm{kg}$ & $\begin{array}{c}\text { Clear ACTH and cortisol responses; all subjects } \\
\text { had headache, cramping, nausea, some vomiting. } \\
\text { Clear ACTH and cortisol responses; most subjects } \\
\text { had nausea; three vomited following PHYSO; } \\
\text { two had cramping following AVP. }\end{array}$ \\
$\begin{array}{c}\text { Four men, } \\
\text { six women }\end{array}$ & $0.2 \mathrm{mg}$ & $12 \mu \mathrm{g} / \mathrm{kg}$ & $0.10 \mathrm{U} / \mathrm{kg}$ & $\begin{array}{c}\text { Clear ACTH and cortisol responses to AVP; } \\
\text { equivocal hormone responses to PHYSO; } \\
\text { no discernible side effects. }\end{array}$ \\
$\begin{array}{c}\text { Four men } \\
\text { four women }\end{array}$ & $0.2 \mathrm{mg}$ & $6 \mu \mathrm{g} / \mathrm{kg}$ & $0.08 \mathrm{U} / \mathrm{kg}$ & $\begin{array}{c}\text { Clear but variable ACTH and cortisol responses; } \\
\text { mild side effects (transient lightheadedness, } \\
\text { headache, nausea) in a few subjects. }\end{array}$ \\
$\begin{array}{c}\text { Four men, } \\
\text { four women }\end{array}$ & $0.2 \mathrm{mg}$ & $8 \mu \mathrm{g} / \mathrm{kg}$ & $0.08 \mathrm{U} / \mathrm{kg}$ & \\
\hline
\end{tabular}

${ }^{a}$ GLYCO IV = glycopyrrolate intravenously.

${ }^{b}$ PHYSO IV = physostigmine intravenously.

${ }^{c} \mathrm{AVP}$ IM $=$ arginine vasopressin intramuscularly.

were used to compare a larger sample of normal women and men.

\section{Subjects}

Fourteen normal women and 14 normal men matched on age and race were studied four times in the Clinical Studies Suite of Allegheny General Hospital. Age- and race-matching were done because of their relationship to HPA axis function (Rubin et al. 1987; Thompson and Rubin 1993). The subjects were recruited from hospital employees, their families and friends, and through public service announcements. The absence of past or present psychiatric illness in each subject was determined with the Structured Clinical Interview for DSMIII-R, Nonpatient Version (SCID-NP) (American Psychiatric Association 1987; Spitzer et al. 1990) conducted by a Master's degree-level psychiatric nurse-clinician and verified by a psychiatrist. If the subject was suitable for study, the Institutional Review Board-approved experimental protocol was explained in detail, and written informed consent was obtained. The Hamilton Depression Rating Scale (Hamilton 1967) also was completed on each subject; their Hamilton scores were all $\leqslant 1$.

A physical assessment, complete blood count, urinalysis and urine screen for common drugs of abuse, blood chemistry panel including thyroid indices, electrocardiogram, and chest X-ray (as indicated or if subject was over 40 years of age) were obtained. Anyone with a history of major medical illness such as hypertension, diabetes, or other endocrinopathy; with abnormal physical or laboratory findings; or who was on any medication that might interfere with the endocrine testing was excluded.

The 14 female subjects had a mean age of $34.8 \pm 9.0$ years (22-52 years). Twelve were caucasian, and two were black. Twelve were premenopausal (two on con- traceptive medication), one was perimenopausal, and one was postmenopausal. The latter two patients were taking conjugated estrogens, 0.625 to $1.25 \mathrm{mg}$ per day. None of the subjects was receiving thyroid replacement. Eleven women were nonsmokers; three smoked 15 to 20 cigarettes per day. The 14 male subjects had a mean age of $35.4 \pm 9.3$ years (22-52 years), and their race was identical to that of the female subjects to whom they were matched. Ten men were nonsmokers, two smoked 10 cigarettes per day, and two smoked 15 to 20 cigarettes per day.

\section{Neuroendocrine Protocol}

This was identical to that of the last dose-finding study, as indicated above, and included four test sessions 5 to 7 days apart, but in the following order: PHYSO $(8 \mu \mathrm{g} /$ $\mathrm{kg}$ iv) plus AVP (0.08 U/kg im), PHYSO alone, saline control, and AVP alone. This order was used because some of the controls were individually matched to patients with major depression who, for clinical reasons, had been studied in the same sequence.

Side effects were quantified on a four-point scale (03; none, mild, moderate, severe) at three times during each session. After the 5:30 P.M. injection (glycopyrrolate) the criteria were $0=$ none, $1=$ metallic taste $/ \mathrm{mild}$ dry mouth; 2 = prolonged mild dry mouth, and $3=$ prolonged severe dry mouth. After the 6 P.M. injection (PHYSO or saline) the criteria were $0=$ none, $1=$ transient lightheadedness/nausea, 2 = prolonged lightheadedness/nausea, and $3=$ vomiting. After the 7 P.M. injection (AVP or saline) the criteria were $0=$ none, $1=$ transient nausea/cramping, 2 = prolonged nausea/ cramping, and 3 = vomiting/flatulence/diarrhea.

All plasma samples from each subject were analyzed in the same $\mathrm{ACTH}_{1-39}$, cortisol, and AVP assays, in duplicate for the first two hormones and in singlet for 
AVP. As mentioned above, parameters of the $\mathrm{ACTH}_{1-39}$ IRMA and cortisol RIA have been described earlier (Rubin et al. 1987, 1995). AVP was determined by a doubleantibody RIA (Glick and Kagan 1979), with materials obtained in kit form (Bühlmann Laboratories, Allschwil, Switzerland). Antibody specificities compared to AVP were lysine vasopressin $0.25 \%$, oxytocin $0.001 \%$, and vasotocin $0.001 \%$. Inter- and intra-assay coefficients of variation were $5.2 \%$ and $8.3 \%$, respectively. The minimum detectable AVP concentration was $0.58 \mathrm{pg} / \mathrm{mL}$ (0.54 pmol/L).

\section{Statistical Analysis}

For $\mathrm{ACTH}_{1-39}$ and cortisol, the samples between 2:30 P.M. and 5:30 P.M. served as the baseline afternoon hormone measures. Afternoon baseline cortisol is an estimator of cortisol secretion comparable to the 24-h average value or the 16-h postdexamethasone value (Thompson et al. 1992). Areas under the curve (AUC) were calculated by the trapezoidal rule and used as the measures of hormone response. For $\mathrm{ACTH}_{1-39}$, the response to PHYSO on the PHYSO-alone and PHYSO/ AVP days was the AUC between 6 P.M.. and 7 P.M., and the response to AVP on the AVP-alone and PHYSO/ AVP days was the AUC between 7 P.M. and 9 P.M. For cortisol, the responses to PHYSO on the PHYSO-alone day and to PHYSO plus AVP on the PHYSO/AVP day were the AUCs between 6 P.M.. and 7 P.M., and for the response to AVP on the AVP-alone day, it was the AUC between 7 P.M. and 10 P.M. These times were chosen based on the times of administration of PHYSO (6 P.M.) and AVP (7 P.M.).

AVP was measured in the samples from 4:30 P.M. to 7 P.M., to ascertain the influence of PHYSO stimulation on endogenous AVP secretion. The samples between 4:30 P.M. and 6 P.M. served as baseline, and the AVP response was calculated as the AUC between 6 P.M. and 7 P.M.

Because the women and men were individually matched on age and race, repeated-measures analyses of variance (ANOVAs) were used to compare the hormone response AUCs by sex and across the test days. Because all hormone values were log-distributed across subjects, the data were log-transformed prior to parametric statistical analysis. Pearson product-moment correlations also were calculated on the log-transformed data. All reported significance levels are twotailed. Statistically significant differences are considered as $p<.05$ and trends as $0.05<p<.10$.

\section{RESULTS}

As mentioned above, 10 women were premenopausal and not taking exogenous hormones, two were taking steroid contraceptives, and two were on estrogen replacement. The hormone measures were compared in the 10 women not taking hormones vs. the four on contraceptives or estrogen replacement. Means for all the hormone measures (ACTH, cortisol, AVP; baselines and responses to stimulation) were very close, and twosample $t$-tests were clearly nonsignificant. These findings are consistent with the study of Aedo et al. (1981), in which women at different menstrual cycle phases and following depot medroxyprogesterone acetate injection had similar cortisol responses to dexamethasone suppression and ACTH stimulation. Thus, in the present study, all 14 women are considered as a single group.

Body surface area (BSA) was significantly less in the women $\left(1.75 \pm 0.13 \mathrm{~m}^{2}\right)$ than in the men $(2.03 \pm 0.24$ $\left.\mathrm{m}^{2}\right)(t=-4.19 ; p<.002)$. Correlations between BSA and baseline and stimulated hormone values in both the women and the men were all of low order, and none was significant. The female-male hormone differences reported below therefore do not appear to be related to the difference in BSA between the two groups of subjects.

\section{Side Effects of Drug Administration}

Table 2 indicates the numbers of female and male subjects having no, mild, or moderate side effects following administration of glycopyrrolate at 5:30 P.M., saline or PHYSO at 6 P.M., and saline or AVP at 7 P.M. Side effects were graded as indicated above and in the table legend. About half the subjects had no side effects, and no subject had severe side effects following any treatment. Three women had moderate reactions to glycopyrrolate, no subject had a moderate reaction to PHYSO, and two women and one man had moderate reactions to administered AVP. All other side effects were rated as mild.

The few moderate side effects were combined with the mild side effects to create dichotomous scores (side effects absent or present), and Wilcoxon signed-rank tests were calculated on these scores. As indicated in Table 2, both PHYSO and AVP produced greater frequencies of side effects in both the women and the men than did the corresponding administrations of saline. Although not indicated in Table 2, several drug-saline differences were statistically significant $(p<.05)$. Neither glycopyrrolate nor PHYSO produced significant female-male differences in frequency of side effects on any of the test days. AVP produced significantly greater side effects in the women on one of the two days in which it was administered.

Of importance, point biserial correlations between side effects (absent or present) after PHYSO administration at 6 P.M. on the PHYSO-alone and PHYSO/AVP days and after AVP administration at 7 P.M. on the 
Table 2. Number of Subjects Having No, Mild, or Moderate Side Effects, Respectively, Following Glycopyrrolate, Physostigmine (PHYSO) and Arginine Vasopressin (AVP) Challenge in 14 Normal Women Compared to 14 Matched Normal Men ${ }^{a}$

\begin{tabular}{|c|c|c|c|}
\hline & $\begin{array}{c}\text { Women }(n=14) \\
\text { None; Mild; Moderate }\end{array}$ & $\begin{array}{c}\text { Men }(n=14) \\
\text { None; Mild; Moderate }\end{array}$ & $\begin{array}{l}\text { Wilcoxon signed- } \\
\text { rank tests }(p)^{b}\end{array}$ \\
\hline \multicolumn{4}{|c|}{ Following Glycopyrrolate at 5:30 P.M. } \\
\hline Saline Control Day & $3 ; 11 ; 0$ & $7 ; 7 ; 0$ & NS \\
\hline \multicolumn{4}{|c|}{ Following Glycopyrrolate at 5:30 P.M. } \\
\hline PHYSO-Alone Day & $4 ; 9 ; 1$ & $8 ; 6 ; 0$ & NS \\
\hline \multicolumn{4}{|c|}{ Following Glycopyrrolate at 5:30 P.M. } \\
\hline AVP-Alone Day & $6 ; 8 ; 0$ & $10 ; 4 ; 0$ & NS \\
\hline \multicolumn{4}{|c|}{ Following Glycopyrrolate at 5:30 P.M. } \\
\hline PHYSO-plus-AVP Day & $3 ; 9 ; 2$ & $8 ; 6 ; 0$ & NS \\
\hline \multicolumn{4}{|l|}{ Following Saline at 6 P.M. } \\
\hline Saline Control Day & $13 ; 1 ; 0$ & $14 ; 0 ; 0$ & NS \\
\hline \multicolumn{4}{|l|}{ Following PHYSO at 6 P.M. } \\
\hline PHYSO-Alone Day & $5 ; 9 ; 0$ & $7 ; 7 ; 0$ & NS \\
\hline \multicolumn{4}{|l|}{ Following Saline at 6 P.M. } \\
\hline AVP-Alone Day & $12 ; 2 ; 0$ & $14 ; 0 ; 0$ & NS \\
\hline \multicolumn{4}{|l|}{ Following PHYSO at 6 P.M. } \\
\hline PHYSO-plus-AVP day & $7 ; 7 ; 0$ & $9 ; 5 ; 0$ & NS \\
\hline \multicolumn{4}{|l|}{ Following Saline at 7 P.M. } \\
\hline Saline Control Day & $13 ; 1 ; 0$ & $14 ; 0 ; 0$ & NS \\
\hline \multicolumn{4}{|l|}{ Following Saline at 7 P.M. } \\
\hline PHYSO-Alone Day & $13 ; 1 ; 0$ & $12 ; 2 ; 0$ & NS \\
\hline \multicolumn{4}{|l|}{ Following AVP at 7 P.M. } \\
\hline AVP-Alone Day & $5 ; 8 ; 1$ & $12 ; 2 ; 0$ & $<.02$ \\
\hline \multicolumn{4}{|l|}{ Following AVP at 7 P.M. } \\
\hline PHYSO-plus-AVP Day & $8 ; 5 ; 1$ & $7 ; 6 ; 1$ & NS \\
\hline
\end{tabular}

${ }^{a}$ Side effects were graded as follows. (No subject had severe side effects following any treatment). Following glycopyrrolate at 5:30 P.M.: $0=$ none; $1=$ metallic taste, mild dry mouth; 2 = prolonged dry mouth; 3 = prolonged severe dry mouth. Following saline or PHYSO at 6 P.M.: $0=$ none; $1=$ mild (transient lightheadedness, nausea); 2 = moderate (prolonged lightheadedness, nausea); $3=$ severe (vomiting). Following saline or AVP at 7 P.M.: 0 = none; 1 = mild (transient nausea, cramping); 2 = moderate (prolonged nausea, cramping); $3=$ severe (vomiting, flatulence, diarrhea).

${ }^{b}$ For the Wilcoxon signed-rank tests, the few moderate side effects were combined with the mild side effects to create dichotomous scores (side effects absent or present), and the statistical tests were run on these scores.

AVP-alone and PHYSO/AVP days, and the corresponding $\mathrm{ACTH}_{1-39}$, cortisol, and AVP responses (AUCs), were all of low order (none $>0.31$ or $<-0.22$ for the women and $>0.24$ or $<-0.26$ for the men), and all were nonsignificant. Thus, the hormone responses reported below cannot be attributed to the occurrence of side effects in either group of subjects.

\section{Baseline Hormone Values and Hormone Responses to Drug Challenge}

Figure 1, Figure 2, and Figure 3 present the mean ( \pm SEM) $\mathrm{ACTH}_{1-39}$, cortisol, and AVP values, respectively, at each time point for the female and matched male controls on the four test days. Afternoon baseline $\mathrm{ACTH}_{1-39}$, cortisol, and AVP did not vary systematically across the four test days (Kendall's coefficients of concordance determined separately for each hormone, and subject group were all $<0.09 ; p=\mathrm{NS}$ ), and baseline hormone coefficients of variation across the four days for both subject groups were all $<5.5 \%$. The fact that the afternoon, baseline values of these stress-responsive hormones were not higher on the first or second test days
(PHYSO/AVP and PHYSO/saline) compared to the third or fourth days (saline/saline and saline/AVP) argues against the possibility that the hormone responses to PHYSO administration were related to the order of testing, i.e., enhanced by the novelty of the experimental situation on the first or second test days. However, it does not completely eliminate this possibility.

With reference to exogenously administered AVP, repeated-measures ANOVAs of log-transformed $\mathrm{ACTH}_{1-39}$ and cortisol responses to AVP vs. saline revealed a significant stimulatory effect of AVP on both hormones (ACTH $p<.0001$; cortisol $p<.0002$ ), but no significant difference in hormone responses between women and men (sex $\times$ treatment interactions: ACTH $p>.60$; cortisol $p>$.15). Therefore, the rest of this article will concern the HPA axis responses to PHYSO.

With reference to PHYSO administration, Table 3 presents the mean $( \pm$ SEM) baseline hormone values and the hormone responses to saline and PHYSO (AUCs) in the female and male subjects. Because the baseline hormone values did not vary systematically across the four test days, as noted above, they were averaged across all four days for each subject. Afternoon 

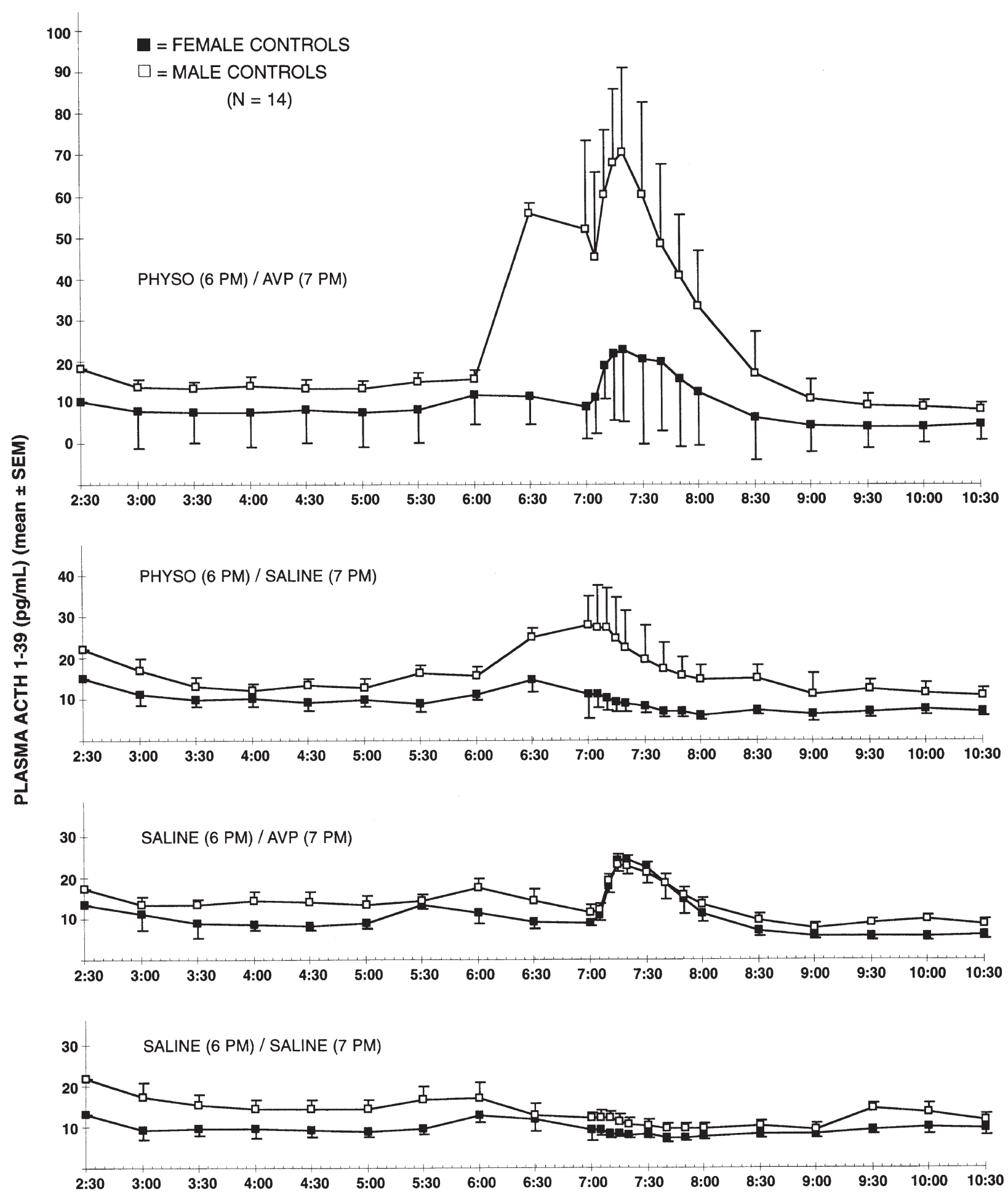

TIME (PM)

Figure 1. Mean ( $\pm \mathrm{SEM}$ ) plasma $\mathrm{ACTH}_{1-39}$ values at each time point (2:30 P.M. to 10:30 P.M.) on the four test days for 14 normal women and 14 matched normal men. Glycopyrrolate was administered on all test days at 5:30P.M.; low doses of physostigmine (PHYSO), arginine vasopressin (AVP), and/or saline were administered on the individual test days as indicated. 


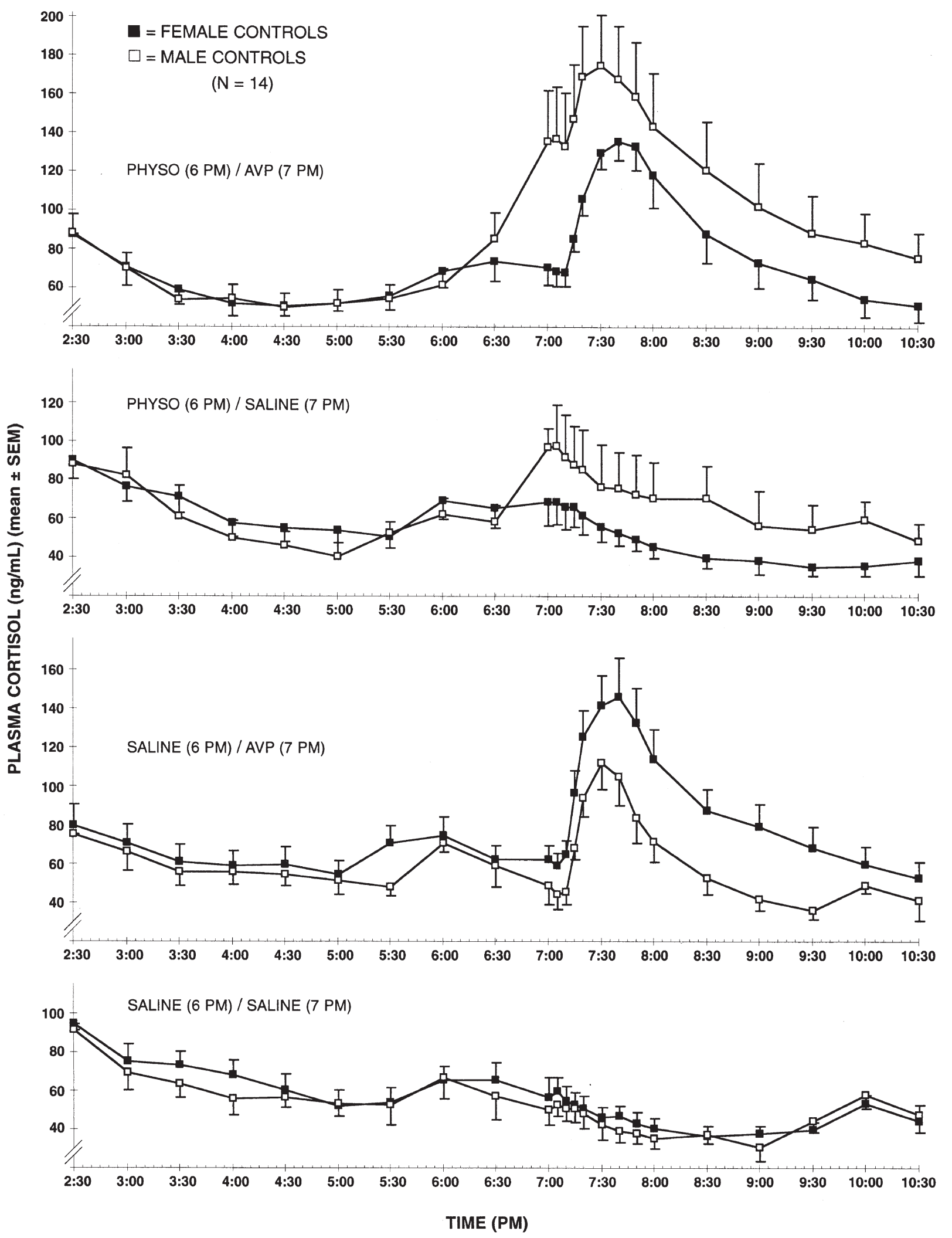

Figure 2. Mean ( \pm SEM) plasma cortisol values at each time point (2:30 P.M. to 10:30 P.M.) on the four test days for 14 normal women and 14 matched normal men. Glycopyrrolate was administered on all test days at 5:30P.M.; low doses of physostigmine (PHYSO), arginine vasopressin (AVP), and/or saline were administered on the individual test days as indicated. 


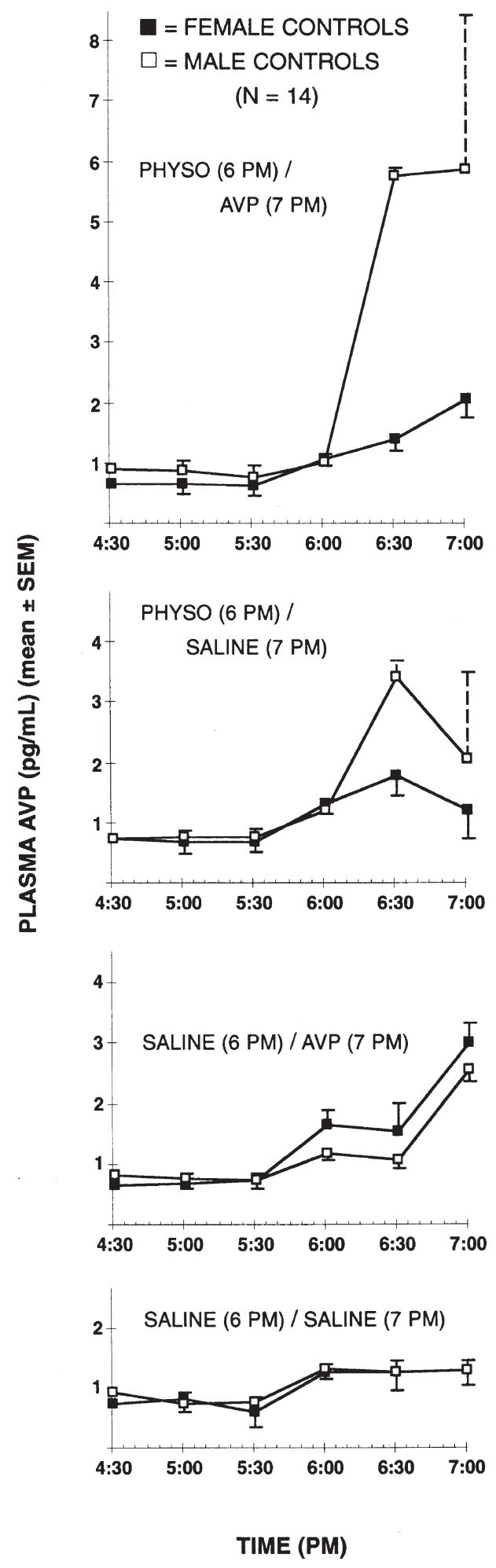

Figure 3. Mean ( \pm SEM) plasma arginine vasopressin (AVP) values at each time point (4:30 P.M. to 7 P.M.) on the four test days for 14 normal women and 14 matched normal men. Glycopyrrolate was administered on all test days at 5:30 P.M.; low doses of physostigmine (PHYSO), AVP, and/ or saline were administered on the individual test days as indicated. baseline $\mathrm{ACTH}_{1-39}$ was significantly higher in the men than in the women (paired $t=-2.12 ; p<.05$ ), but baseline cortisol and AVP were not significantly different between groups (paired $t=0.88$ and -0.96 , respectively).

Table 4 presents the results of repeated-measures ANOVAs of the log-transformed $\mathrm{ACTH}_{1-39}$, cortisol, and AVP responses (AUCs) to PHYSO vs. saline in the female vs. the male subjects. For the PHYSO vs. saline comparisons, the hormone responses on the two days in which PHYSO was administered at 6 P.M. were contrasted with the two days in which saline was given at 6 P.M.

PHYSO significantly increased the secretion of all three hormones $(p=.025, .03$, and .0001 , respectively; Figure 1-3). For $\mathrm{ACTH}_{1-39}$, there were both a significant sex difference $(p=.04)$ and a sex $\times$ treatment interaction $(p=.01)$; the response to PHYSO was clearly higher in the men (Table 3 and Figure 1). For cortisol, there was no significant sex difference $(p=.87)$, but a trend toward a sex $\times$ treatment interaction $(p=.08$; Figure 2). For AVP, as for $\mathrm{ACTH}_{1-39}$, there were both a significant sex difference $(p=.02)$ and a sex $\times$ treatment interaction ( $p=.02)$; again, the response to PHYSO was higher in the men (Table 3 and Figure 3). Correlations between the $\mathrm{ACTH}_{1-39}$ and AVP responses to PHYSO on the PHYSO-alone and PHYSO/AVP days in the women were 0.23 and -0.18 , respectively $(p=\mathrm{NS})$, but in the men they were 0.70 and 0.70 , these being statistically significant $(p<.01)$.

\section{DISCUSSION}

Previous studies of sex differences in HPA axis responsiveness to direct stimuli such as exogenous CRH and AVP administration have found either no difference or greater responses in women (Carroll et al. 1993; Heuser et al. 1994; Born et al. 1995). In most studies of central cholinergic stimulation of the HPA axis, however, the sex of the subjects was not specified, or only men were used (Carroll et al. 1980; Davis et al. 1982; Nurnberger et al. 1983; Risch et al. 1983; Lewis et al. 1984; Raskind et al. 1989; 1990; Dodt et al. 1994). Doerr and Berger (1983) and Krieg et al. (1987) did include both women and men in their studies but did not analyze their results by sex.

The results of our study indicate a greater sensitivity of the HPA axis to low-dose PHYSO in normal men compared to normal women. The men did not experience more side effects than did the women; therefore, this greater sensitivity in the men does not appear to be due to nonspecific stress. The results also suggest that the $\mathrm{ACTH}_{1-39}$ response in the men may have been mediated by increased secretion of AVP because this hormone also responded to PHYSO in the men significantly more than in the women, and, in the men, AVP 
Table 3. Baseline $\mathrm{ACTH}_{1-39}$, Cortisol, and AVP and Hormone Responses to Physostigmine (PHYSO) Challenge in 14 Normal Women Compared to 14 Matched Normal $\mathrm{Men}^{a}$

\begin{tabular}{|c|c|c|}
\hline & $\begin{array}{l}\text { Women } \\
(n=14)\end{array}$ & $\begin{array}{c}\text { Men } \\
(n=14)\end{array}$ \\
\hline \multicolumn{3}{|l|}{ Baseline $\mathrm{ACTH}_{1-39}$ 2:30-6 P.M. (pg/mL) } \\
\hline Average of All Four Days & $10.1 \pm 1.4$ & $15.4 \pm 1.7$ \\
\hline \multicolumn{3}{|l|}{$\mathrm{ACTH}_{1-39} \mathrm{AUC}^{b}(\mathrm{pg} / \mathrm{mL} \times \min )$} \\
\hline After Saline on Saline/Saline Day & $685 \pm 134$ & $824 \pm 100$ \\
\hline \multicolumn{3}{|l|}{$\mathrm{ACTH}_{1-39} \mathrm{AUC}^{b}(\mathrm{pg} / \mathrm{mL} \times \min )$} \\
\hline After Saline on Saline/AVP Day & $590 \pm 63$ & $878 \pm 108$ \\
\hline \multicolumn{3}{|l|}{$\mathrm{ACTH}_{1-39} \mathrm{AUC}^{b}(\mathrm{pg} / \mathrm{mL} \times \min )$} \\
\hline After PHYSO on PHYSO-Alone Day & $782 \pm 253$ & $1412 \pm 374$ \\
\hline \multicolumn{3}{|l|}{$\mathrm{ACTH}_{1-39} \mathrm{AUC}^{b}(\mathrm{pg} / \mathrm{mL} \times \min )$} \\
\hline After PHYSO on PHYSO/AVP Day & $666 \pm 124$ & $2702 \pm 958$ \\
\hline \multicolumn{3}{|l|}{ Baseline Cortisol 2:30-6 P.M. (ng/mL) } \\
\hline Average of All Four Days & $66 \pm 5.1$ & $61 \pm 3.3$ \\
\hline \multicolumn{3}{|l|}{ Cortisol AUC ${ }^{b}(\mathrm{ng} / \mathrm{mL} \times \min )$} \\
\hline After Saline on Saline/Saline Day & $3816 \pm 527$ & $3478 \pm 464$ \\
\hline \multicolumn{3}{|l|}{ Cortisol $\mathrm{AUC}^{b}(\mathrm{ng} / \mathrm{mL} \times \min )$} \\
\hline After Saline on Saline/AVP Day & $3936 \pm 400$ & $3587 \pm 544$ \\
\hline \multicolumn{3}{|l|}{ Cortisol $\mathrm{AUC}^{b}(\mathrm{ng} / \mathrm{mL} \times \mathrm{min})$} \\
\hline After PHYSO on PHYSO-Alone Day & $4063 \pm 620$ & $4164 \pm 651$ \\
\hline \multicolumn{3}{|l|}{ Cortisol $\mathrm{AUC}^{b}(\mathrm{ng} / \mathrm{mL} \times \min )$} \\
\hline After PHYSO on PHYSO/AVP Day & $4316 \pm 475$ & $5545 \pm 798$ \\
\hline \multicolumn{3}{|l|}{ Baseline AVP 4:30-6 P.M. (pg/mL) } \\
\hline Average of All Four Days & $0.86 \pm 0.20$ & $0.90 \pm 0.11$ \\
\hline \multicolumn{3}{|l|}{$\operatorname{AVP} \operatorname{AUC}^{b}(\mathrm{pg} / \mathrm{mL} \times \min )$} \\
\hline After Saline on Saline/Saline Day & $76 \pm 17$ & $77 \pm 11$ \\
\hline \multicolumn{3}{|l|}{$\operatorname{AVP~AUC}^{b}(\mathrm{pg} / \mathrm{mL} \times \min )$} \\
\hline After Saline on Saline/AVP Day & $108 \pm 26$ & $89 \pm 17$ \\
\hline \multicolumn{3}{|l|}{$\operatorname{AVP~AUC}^{b}(\mathrm{pg} / \mathrm{mL} \times \min )$} \\
\hline After PHYSO on PHYSO-Alone Day & $92 \pm 20$ & $152 \pm 56$ \\
\hline \multicolumn{3}{|l|}{$\operatorname{AVP} \operatorname{AUC}^{b}(\mathrm{pg} / \mathrm{mL} \times \min )$} \\
\hline After PHYSO on PHYSO/AVP Day & $98 \pm 20$ & $478 \pm 243$ \\
\hline
\end{tabular}

responses were significantly positively correlated with their $\mathrm{ACTH}_{1-39}$ responses.

A critical issue in the present study is defining a putative mechanism for the observed sex difference in AVP response to cholinergic stimulation, which paralleled the $\mathrm{ACTH}_{1-39}$ response. The ratio of the two hormone responses was similar to that after infusion of hypertonic saline into normal men (Rittmaster et al. 1987), again suggesting that stimulation of AVP by PHYSO was a major stimulus to ACTH secretion in our subjects.

Muscarinic neurotransmission appears to be involved in cholinergic stimulation of AVP secretion because scopolamine, a centrally active muscarinic cholinergic antagonist, blocked the AVP response to PHYSO in normal men, but mecamylamine, a centrally active nicotinic antagonist, did not (Pascualy et al. 1995). Of putative relevance is the cholinergic basal forebrain complex, which projects, among other areas, to the amygdala and hippocampus, important areas for stimulation and negative feedback, respectively, of the HPA axis (Fibiger et al. 1991; Wainer et al. 1993), but it is difficult to propose a detailed neurophysiological and neuroanatomical model for our results.

For example, there is electrophysiological evidence for direct connections between the lateral septum and amygdala and the ipsilateral paraventricular and supraoptic nuclei, which are inhibitory to AVP neurons in these nuclei (Poulain et al. 1981; Cirino and Renaud 1985; Baldino et al. 1988). In rats, the lateral septum (as well as ventral septum, lateral habenular nucleus, and midbrain structures) receives input from sexually dimorphic vasopressinergic cells in the bed nucleus of the stria terminalis (BNST) and medial amygdala (De Vries et al. 1994a; 1994b). The number of sexually dimorphic vasopressinergic cells and the density of their innervations are greater in male animals than in females, and expression of AVP is maintained by testosterone through both androgen and estrogen receptors (the latter via aromatization of testosterone).

The functional relationships of these circuits, however, are largely still unknown. In humans, the BNST 
Table 4. Repeated Measures Analyses of Variance of Log-Transformed $\mathrm{ACTH}_{1-39}, \mathrm{AVP}$, and Cortisol Responses to Physostigmine (PHYSO) vs. Saline Challenge in 14 Normal Women Compared to 14 Matched Normal Men ${ }^{a}$

\begin{tabular}{|c|c|c|c|c|c|}
\hline Source of Variation & Sum of Squares & d.f. & Mean Square & $\mathbf{F}$ & $P$ \\
\hline \multicolumn{6}{|l|}{$\mathrm{ACTH}_{1-39}$} \\
\hline PHYSO vs. Saline $e^{b}$ & 0.313 & 1 & 0.313 & \multirow[t]{2}{*}{6.39} & \multirow[t]{2}{*}{.025} \\
\hline Error & 0.636 & 13 & 0.049 & & \\
\hline Women vs. Men & 1.815 & 1 & 1.815 & \multirow[t]{2}{*}{5.09} & \multirow[t]{2}{*}{.04} \\
\hline Error & 4.631 & 13 & 0.356 & & \\
\hline Sex $\times$ Treatment & 0.374 & 1 & 0.374 & \multirow[t]{2}{*}{8.40} & \multirow[t]{2}{*}{.01} \\
\hline Error & 0.579 & 13 & 0.044 & & \\
\hline \multicolumn{6}{|l|}{ Cortisol } \\
\hline PHYSO vs. Saline ${ }^{b}$ & 0.175 & 1 & 0.175 & \multirow[t]{2}{*}{5.83} & \multirow[t]{2}{*}{.03} \\
\hline Error & 0.391 & 13 & 0.030 & & \\
\hline Women vs. Men & 0.004 & 1 & 0.004 & \multirow[t]{2}{*}{0.03} & \multirow[t]{2}{*}{.87} \\
\hline Error & 1.860 & 13 & 0.143 & & \\
\hline Sex $\times$ Treatment & 0.070 & 1 & 0.070 & \multirow[t]{2}{*}{3.55} & \multirow[t]{2}{*}{.08} \\
\hline Error & 0.257 & 13 & 0.020 & & \\
\hline \multicolumn{6}{|l|}{ AVP } \\
\hline PHYSO vs. Saline $\mathrm{e}^{b}$ & 0.831 & 1 & 0.831 & \multirow[t]{2}{*}{30.53} & \multirow[t]{2}{*}{.0001} \\
\hline Error & 0.327 & 13 & 0.027 & & \\
\hline Women vs. Men & 0.506 & 1 & 0.506 & \multirow[t]{2}{*}{6.88} & \multirow[t]{2}{*}{.02} \\
\hline Error & 0.884 & 13 & 0.074 & & \\
\hline Sex $\times$ Treatment & 0.505 & 1 & 0.505 & \multirow[t]{2}{*}{6.05} & \multirow[t]{2}{*}{.03} \\
\hline Error & 0.579 & 13 & 0.044 & & \\
\hline
\end{tabular}

${ }^{a} \mathrm{ACTH}_{1-39}, \mathrm{AVP}$, and cortisol AUCs for response to PHYSO vs. saline = area under the curve 6 P.M. -7 P.M.

${ }^{b}$ Comparison of response to PHYSO vs. saline = contrast of two saline control days vs. two PHYSO administration days.

contains AVP-immunoreactive cells, and the nucleus basalis of Meynert, part of the basal forebrain cholinergic complex, may contain scattered cells expressing AVP messenger RNA (Sukhov et al. 1993). Whether these cells in the human are sexually dimorphic and/or hormone sensitive also is unknown. Furthermore, there are other sexually dimorphic areas of the brain in both rats and humans, the most prominent being in the preoptic area of the hypothalamus (Swaab 1995; Swaab et al. 1995), which also has been implicated in HPA axis regulation (Viau and Meaney 1996; Herman et al. 1996). Because these systems receive direct or indirect cholinergic input, they may mediate the effects of PHYSO on the HPA axis differently in females and males.

There also may be an important effect of age on sex differences in HPA axis responsiveness to cholinergic stimulation. Peskind et al. (1996) measured immunoreactive ACTH, $\beta$-endorphin-like immunoreactivity, and cortisol responses to PHYSO in female and male patients with Alzheimer's disease and normal older-adult controls. There were no differences between patients and controls in any hormone response, but the female patients and controls as a group $(n=8)$ had significantly greater responses of all three hormones than did the male subjects as a group $(n=13)$. These findings are the opposite of ours.
There are several possible reasons for this difference. First, the average age of the Peskind et al. subjects was $71 \pm 2$ years, twice that of our subjects. The sensitivity of the HPA axis to stimulation increases somewhat with age, but it is not clear if this occurs differentially in women and men. Only three of their eight elderly women were receiving estrogen replacement; our preliminary findings on postmenopausal, nonestrogen-replaced women suggest that they may have greater responses to low-dose PHYSO than do younger women. Second, Peskind et al. (1996) quantitated side effects to PHYSO and indicated there was no significant difference in nausea ratings between men and women, but the severity of side effects was not noted, i.e., how many subjects may have had nausea and vomiting and thus a nonspecific stress stimulation of the HPA axis.

Finally, in our younger subjects, AVP as well as $\mathrm{ACTH}_{1-39}$ responded to PHYSO to a greater degree in the men, and the two responses were significantly correlated, suggesting that increased AVP may have been an intermediary between the cholinergic stimulus and the ACTH response (Peskind et al. did not measure AVP in their elderly subjects). AVP-producing cells in the human supraoptic and paraventricular nuclei remain intact in old age (Hofman 1997), and basal plasma AVP concentrations have been reported to be twice as 
high in elderly men as in elderly women (Asplund and Åberg 1991). However, in aged male rats the density of high-affinity hypothalamic acetylcholine binding sites is decreased, whereas in aged female rats it is preserved, suggesting a potential decrease in responsiveness to cholinergic challenge in aged male animals (Gurwitz et al. 1987).

In conclusion, the present study suggests that central cholinergic systems can influence AVP secretion differentially in young adult women and men. Either central cholinergic systems themselves may be sexually dimorphic, or central cholinergic stimulation can affect other, sexually dimorphic systems that influence hormone release. The available evidence, although scanty, points toward the latter. We currently are extending the lowdose PHYSO protocol to elderly women and men, and subsequent studies will address specific muscarinic and nicotinic components of this system in both young and elderly subjects.

\section{ACKNOWLEDGMENTS}

Dr. Geert De Vries provided important consultative advice on the manuscript. This study was supported by National Institute of Mental Health research grant MH28380 and Research Scientist Award MH47363 (to R.T.R.).

\section{REFERENCES}

Aedo AR, Landgren BM, Diczfalusy E (1981): Studies on ovarian and adrenal studies at different phases of the menstrual cycle IV. The effect of dexamethasone suppression and subsequent ACTH stimulation at different phases of the menstrual cycle and following the administration of $150 \mathrm{mg}$ of depot-medroxy-progrsterone acetate (DMPA). Contraception 24:543-558

American Psychiatric Association (1987): Diagnostic and Statistical Manual of Mental Disorders (Third EditionRevised). Washington DC, American Psychiatric Press

Antoni FA (1993): Vasopressinergic control of pituitary adrenocorticotropin secretion comes of age. Front Neuroendocrinol 14:76-122

Asplund R, Åberg H (1991): Diurnal variation in the levels of antidiuretic hormone in the elderly. J Int Med 229:131134

Assenmacher I, Szafarcyzk A, Alonso G, Ixart G, Barbanel G (1987): Physiology of neural pathways affecting CRH secretion. Ann NY Acad Sci 512:149-161

Baldino F Jr, O'Kane TM, Fitzpatrick-McElligott S (1988): Coordinate hormonal and synaptic regulation of vasopressin messenger RNA. Science 241:978-981

Born J, Ditschuneit I, Schreiber M, Dodt C, Fehm HL (1995): Effects of age and gender on pituitary-adrenocortical responsiveness in humans. Eur J Endocrinol 132:705-711

Calogero AE (1995): Neurotransmitter regulation of the hypothalamic corticotropin-releasing hormone neuron. Ann NY Acad Sci 771:31-40

Carroll BJ, Greden JF, Haskett R, Feinberg M, Albala AA, Martin FI, Rubin RT, Heath B, Sharp PT, McLeod WL, McLeod MF (1980): Neurotransmitter studies of neuroendocrine pathology in depression. Acta Psychiatr Scand Suppl 280:183-199

Carroll BT, Meller WH, Kathol RG, Gehris TL, Carter JL, Samuelsen SD, Pitts AF (1993): Pituitary-adrenal axis response to arginine vasopressin in patients with major depression. Psychiatry Res 46:119-126

Cirino M, Renaud LP (1985): Influence of lateral septum and amygdala stimulation on the excitability of hypothalamic supraoptic neurons: An electrophysiological study in the rat. Brain Res 326:357-361

Coiro V, Volpi R, Capretti L, Colla R, Caffarri G, Vescovi PP, Chiodera P (1995): Dopaminergic and cholinergic control of arginine-vasopressin secretion in type I diabetic men. Eur J Clin Invest 25:412-417

Davis BM, Brown GM, Miller M, Friesen HG, Kastin AJ, Davis KL (1982): Effects of cholinergic stimulus on pituitary hormone release. Psychoneuroendocrinology 7: 347-354

De Vries GJ, Wang Z, Bullock NA, Numan S (1994a): Sex differences in the effects of testosterone and its metabolites on vasopressin messenger RNA levels in the bed nucleus of the stria terminalis of rats. J Neurosci 14:1789-1794

De Vries GJ, Al-Shamma HA, Zhou L (1994b): The sexually dimorphic vasopressin innervation of the brain as a model for steroid modulation of neuropeptide transmission. Ann NY Acad Sci 743:95-120

Dilsaver SC (1986): Pathophysiology of "cholinoceptor supersensitivity" in affective disorders. Biol Psychiatry 21:813-829

Dodt C, Hansen K, Uthgennant D, Born J, Fehm HL (1994): Cholinergic potentiation of the meal-related rise in ACTH and cortisol concentrations in men. Exp Clin Endocrinol 102:460-466

Doerr P, Berger M (1983): Physostigmine-induced escape from dexamethasone suppression in normal adults. Biol Psychiatry 18:261-268

Fibiger HC, Damsma G, Day JC (1991): Behavioral pharmacology and biochemistry of central cholinergic neurotransmission. In Napier TC, Kalivas PW, Hanin I (eds), The Basal Forebrain. New York, Plenum Press, pp 399-414

Freeman E, Touze R, Grossman A, Besser M, Ross R (1990): Pyridostigmine, an acetyl-cholinesterase inhibitor, stimulates growth hormone release, but has no effect on basal thyrotrophin or adrenocorticotrophin levels, or the thyrotrophin response to thyrotrophin-releasing hormone. J Neuroendocrinol 2:429-432

Gispen-de Wied CC, Westenberg HGM, Koppeschaar HPF, Thijssen JHH, van Ree JM (1992): Stimulation of the pituitary-adrenal axis with a low dose [Arg 8 -vasopressin in depressed patients and healthy subjects. Eur Neuropsychopharmacol 2:411-419

Glick SM, Kagan A (1979): Radioimmunoassay of arginine vasopressin. In Jaffe BM, Behrmann HR (eds), Methods 
of Hormone Radioimmunoassays. New York, Academic Press, pp 341-351

Gregg CM (1985): The compartmentalized hypothalamoneurohypophysial system: evidence for a neurohypophysial action of acetylcholine on vasopressin release. Neuroendocrinology 40:423-429

Gurwitz D, Egozi Y, Henis YI, Kloog Y, Sokolovsky M (1987): Agonist and antagonist binding to rat brain muscarinic receptors: Influence of aging. Neurobiol Aging 8:115-122

Hamilton M (1967): Development of a rating scale for primary depressive illness. Br J Soc Clin Psychol 6:278-296

Herman JP, Prewitt CM, Cullinan WE (1996): Neuronal circuit regulation of the hypothalamo-pituitary-adrenocortical stress axis. Crit Rev Neurobiol 10:371-394

Heuser IJ, Gotthardt U, Schweiger U, Schmider J, Lammers CH, Dettling M, Holsboer F (1994): Age-associated changes of pituitary-adrenocortical hormone regulation in humans: Importance of gender. Neurobiol Aging 15:227-231

Hofman MA (1997): Lifespan changes in the human hypothalamus. Exp Gerontol 32:559-575

Janowsky DS, Overstreet DH (1995): The role of acetylcholine mechanisms in mood disorders. In Bloom FE, Kupfer DJ (eds), Psychopharmacology: The Fourth Generation of Progress. New York, Raven Press, pp 945-956

Kathol RG, Jaeckle RS, Lopez JF, Meller WH (1989): Consistent reduction of $\mathrm{ACTH}$ responses to stimulus with $\mathrm{CRH}$, vasopressin and hypoglycaemia in patients with major depression. Br J Psychiatry 155:468-478

Koch KL, Summy-Long J, Bingaman S, Sperry N, Stern RM (1990): Vasopressin and oxytocin responses to illusory self-motion and nausea in man. J Clin Endocrinol Metab 71:1269-1275

Kohl RL (1992): Beta-endorphin and arginine vasopressin following stressful sensory stimuli in man. Aviat Space Environ Med 63:986-993

Krieg J-C, Bossert S, Pirke K-M, von Zerssen D, Berger M (1987): The influence of the muscarinic agonist RS 86 on the cortisol system. Biol Psychiatry 22:573-582

Lewis DA, Sherman BM, Kathol RG (1984): Analysis of the specificity of physostigmine stimulation of adrenocorticotropin in man. J Clin Endocrinol Metab 58:570-573

Michels KM, Meeker RB, Hayward JN (1991): Muscarinic cholinergic control of vasopressin secretion from the acute hypothalamoneurohypophysial explant. Neuroendocrinology 54:219-226

Nurnberger JI Jr, Jimerson DC, Simmons-Alling S, Tamminga C, Nadi NS, Lawrence D, Sitaram N, Gillin JC, Gershon ES (1983): Behavioral, physiological, and neuroendocrine responses to arecoline in normal twins and "well state" bipolar patients. Psychiatry Res 9:191-200

Nussey SS, Hawthorn J, Page SR, Ang VT, Jenkins JS (1988): Responses of plasma oxytocin and arginine vasopressin to nausea induced by apomorphine and ipecacuanha. Clin Endocrinol 28:297-304

Ohmori N, Itoi K, Tozawa F, Sakai Y, Sakai K, Horiba N, Demura H, Suda T (1995): Effect of acetylcholine on corticotropin-releasing factor gene expression in the hypothalamic paraventricular nucleus of conscious rats. Endocrinology 136:4858-4863
Okuda H, Shioda S, Nakai Y, Nakayama H, Okamoto M, Nakashima T (1993): The presence of corticotropinreleasing factor-like immunoreactive synaptic vesicles in axon terminals with nicotinic acetylcholine receptorlike immunoreactivity in the median eminence of the rat. Neurosci Lett 161:183-186

Pascualy M, Peskind ER, Wingerson D, van Belle G, Veith RC, Dorsa DM, Raskind MA (1995): Lack of cholinergic regulation of vasopressin and norepinephrine responses to hypertonic saline in humans. Psychoneuroendocrinology 20:679-691

Peskind ER, Raskind MA, Wingerson D, Pascualy M, Thal LJ, Dobie DJ, Wilkinson CW (1996): Hypothalamic-pituitaryadrenocortical axis responses to physostigmine: Effects of Alzheimer's disease and gender. Biol Psychiatry 40:61-68

Poulain DA, Lebrun CJ, Vincent JD (1981): Electrophysiological evidence for connections between septal neurones and the supraoptic nucleus of the hypothalamus of the rat. Exp Brain Res 42:260-268

Raskind MA, Peskind ER, Veith RC, Risse SC, Lampe TH, Borson S, Gumbrecht G, Dorsa DM (1989): Neuroendocrine responses to physostigmine in Alzheimer's disease. Arch Gen Psychiatry 46:535-540

Raskind MA, Peskind ER, Veith RC, Wilkinson CW, Federighi D, Dorsa DM (1990): Differential effects of aging on neuroendocrine responses to physostigmine in normal men. J Clin Endocrinol Metab 70:1420-1425

Risch SC, Janowsky DS, Gillin JC (1983): Muscarinic supersensitivity of anterior pituitary ACTH and $\beta$-endorphin release in major depressive illness. Peptides 4:789-792

Rittmaster RS, Cutler GB, Gold PW, Brandon DD, Tomai T, Loriaux DL, Chrousos GP (1987): The relationship of saline-induced changes in vasopressin secretion to basal and corticotropin-releasing hormone-stimulated adrenocorticotropin and cortisol secretion in man. J Clin Endocrinol Metab 64:371-376

Rivier C, Smith M, Vale W (1990): Regulation of adrenocorticotropic hormone (ACTH) secretion by corticotropin releasing factor (CRF). In De Souza EB, Nemeroff CB (eds), Corticotropin Releasing Factor: Basic and Clinical Studies of a Neuropeptide. Boca Raton, CRC Press, pp 175-203

Rubin RT, Poland RE, Lesser IM, Winston RA, Blodgett ALN (1987): Neuroendocrine aspects of primary endogenous depression I: Cortisol secretory dynamics in patients and matched control subjects. Arch Gen Psychiatry 44:329-336

Rubin RT, Phillips JJ, Sadow TF, McCracken JT (1995): Adrenal gland volume in major depression: Increase during the depressive episode and decrease with successful treatment. Arch Gen Psychiatry 52:213-218

Salata RA, Jarrett DB, Verbalis JG, Robinson AG (1988): Vasopressin stimulation of adrenocorticotropin hormone $(\mathrm{ACTH})$ in humans. J Clin Invest 81:766-774

Spitzer RL, Williams JBW, Gibbon M, First MB (1990): Structured Clinical Interview for DSM-III-R. Washington DC, American Psychiatric Press

Sukhov RR, Walker LC, Rance NE, Price DL, Young WS III (1993): Vasopressin and oxytocin gene expression in the human hypothalamus. J Comp Neurol 337:295-306 
Swaab DF (1995): Development of the human hypothalamus. Neurochem Res 20:509-519

Swaab DF, Gooren LJ, Hofman MA (1995): Brain research, gender and sexual orientation. J Homosexuality 28:283301

Thompson LM, Rubin RT (1993): Neuroendocrine aspects of primary endogenous depression XIII: Influence of race on differences in hypothalamo-pituitary-adrenal and pituitary-thyroid function between patients and matched controls. Biol Psychiatry 34:893-895

Thompson LM, Rubin RT, McCracken JT (1992): Neuroendocrine aspects of primary endogenous depression XII: Receiver operating characteristic and kappa analyses of serum and urine cortisol measures in patients and matched controls. Psychoneuroendocrinology 17: 507515
Tsagarakis S, Grossman A (1990): Central neuroregulation of hypothalamic corticotropin-releasing hormone (CRH41) secretion. J Endocrinol Invest 13:765-775

Tuomisto J, Männistö P (1985): Neurotransmitter regulation of anterior pituitary hormones. Pharmacol Rev 37:249-332

Viau V, Meaney MJ (1996): The inhibitory effect of testosterone on hypothalamic-pituitary-adrenal responses to stress is mediated by the medial preoptic area. J Neurosci 16:1866-1876

Wainer BH, Steininger TL, Roback JD, Burke-Watson MA, Mufson EJ, Kordower J (1993): Ascending cholinergic pathways: Functional organization and implications for disease models. Progr Brain Res 98:9-30

Whitnall MH (1993): Regulation of the hypothalamic corticotropin-releasing hormone neurosecretory system. Progr Neurobiol 40:573-629 